\title{
ADAPTIVE CHANGES IN SPEECH PERCEPTION
}

\author{
Olga D. VolcheK
}

Saint Petersburg Institute of Humanities, Russia, Saint Petersburg

\begin{abstract}
The influence of individual characteristics on speech perception was studied in relation to weather conditions. Parameters of emotional and color images for 12 masculine names and 6 vowel sounds were used for experimental models. In the period of 1 February - 7 June 2013, 20 women and 6 men, all residents of St.Petersburg, were filling in a special form, estimating the offered parameters of the emotional image by a 5 -score scale and registering their color associations. The data collected during 23 days of the experiment were matched with the indices of local and cosmic weather and compared with individual characteristics: gender, the diurnal chronotype by A.A. Putilov («skylark», «dove», «owl»). Mathematical processing included t-criterion, the Fisher criterion and correlation analysis.

Significant and valid adaptive changes in the parameters of images of sounds and names were detected in relation to the part of day, season and weather conditions $(p \leq 0.05 \div 0.001)$. Characteristics of the pronunciation of a certain vowel or a name influenced their perception under different environmental conditions. There were significant differences in the studied parameters of speech perception between men and women, which correspond to the higher sensitivity of male organisms to environmental conditions, and between people with different diurnal chronotypes $(p \leq 0,05 \div 0,001)$.
\end{abstract}

Keywords: adjustment, part of day, speech perception, personal name, image of name, weather, gender, diurnal chronotype.

\section{INTRODUCTION}

The wholesome images of the world transmitted via speech and music reflect the global characteristics of physical environment, including temperature, 
atmospheric parameters, gravity, magnetic and electromagnetic fields [2]. The sensation of any modality can be associated with sensations in the speech apparatus [1]. A. P. Zhuravlev discovered the value shift phenomenon: words with positive semantic meaning associate with more negative emotional images, and vice versa. It can lead to a less frequent usage of a word, as well as of a personal name, or even to its disappearance from speech [6].

It is reasonable to think that changes in psychophysiological state and the articulation apparatus, provoked by changes in natural environment, can in some ways influence speech perception and the value shift phenomenon.

It has been shown that the values of the indexes of emotional and color images of vowels and men names vary in correlation with the time of the day and a set of weather conditions $[5,12]$. This article is aimed at describing the main results of studying the influence of natural environment and personal characteristics onto speech perception.

\section{METHODS AND MATERIALS}

Emotional and color images of personal names and vowels were taken for an experimental model. Resources of web science were engaged. 20 women and 6 men, all residents of Saint Petersburg, Russia, were filling in the received by email form on the designated day but at any convenient for them time, estimating 12 men names ${ }^{1}$ and 6 vowel sounds. The positions of names and vowels in the list were regularly and randomly changed. The respondents were given the following directions: «Judging by the way the name or vowel sounds, give the indicated parameter scores from 0 to 5 , according to your opinion. Also write one or two associating colors for each name and each vowel. Try not to think too long but mark the first values that come to your mind. It can be at random but must be in silence».

The experiment lasted from 1 February 2013 to 7 June 2013. The collected data were grouped by the time of the day, by the experimental days and compared with a range of the main local and global environmental parameters.

The local environmental parameters included the time of the day, weather conditions in Saint Petersburg http://PogodaSpb.info (air temperature, $\mathrm{C}^{\circ}$; atmospheric pressure, $\mathrm{mm} \mathrm{Hg}$, wind speed, $\mathrm{m} / \mathrm{s}$; humidity, \%; precipitation, $\mathrm{mm}$, and the duration of daylight (DD), min. The cosmic weather parameters we used were the number of solar spots W http://sidc.oma.be/products/mobu/; geomagnetic activity index Dst http://wdc.kugi.kyoto-u.ac.jp/dstdir/; magnetic

\footnotetext{
${ }^{1}$ Alexandr, Vladimir, Dmitriy, Yegor, Ilya, Kirill, Mikhail, Nikita, Pyotr, Svyatoslav, Seraphim, Serguey; A [a], Е [e], И [i], О [o], У [u], Ы [specific Russian vowel].
} 
field of the Sun as a star SMF http://wso.stanford.edu/; radio flux index 10,7 cm; averaged geomagnetic disturbance indices $\mathrm{A}$ and $\mathrm{Kp}(\mathrm{nT}) \mathrm{http}: / /$ www.tesis.lebedev.ru/magnetic_storms.html/; gravity index G, which is a long-period component of the potential of the tidal power of the Moon and the Sun. The values of the index $\mathrm{G}$ were calculated by L. N. Petrova, PhD in Physics and Mathematics, and I would like to express my deep gratitude for her help.

Free color associations were grouped by the main color and their shades. 15 color groups were involved: Black, Gray, White, Pink-Lilac, Red, Crimson, Yellow, Orange, Beige, Chartreuse, Green, Blue, Dark Blue, Violet.

When analyzing the influence of individual traits onto speech perception, gender and the diurnal chronotype of the respondents were taken into consideration. We used the questionnaire Late Bird or Early Bird by A. A. Putilov [8] to identify the respondents' diurnal chronotype.

The mathematical analysis of the data was performed with Statistica 6.0 software, engaging t-criterion, the Fisher criterion $\varphi^{*}$ and correlation analysis.

\section{RESULTS AND DISCUSSION}

The time of the day. For the data from 1 February to 5 April the averaged values for names at different times of the day were calculated. Sample sizes for names were 726 (morning), 924 (afternoon), 1,006 (evening), 784 (night). All the indices of emotional and color image for names and vowels significantly varied depending on the time of the day.

Figures 1 and 2 demonstrate diurnal variations in the values of the indices Melodicism and Good, respectively, for all the respondents regardless their gender. There are significant and valid differences between the lowest and the highest values - extremes - of the index Good for 9 of 12 names studied. The highest values of the indices Melodicism and Good belong to the name Alexandr, which corresponds to the notices by P. A. Florenskiy [9].

The collected data for the period from 1 February to 5 April were grouped regarding the time of the day they were given and processed for each name regarding the gender and the diurnal chronotype of respondents. The number of respondents in each of four chronotype groups varied from 571 to 766 for women and from 142 to 240 for men. The number of respondents in each group varied from 225 to 394 for "early birds", from 131 to 288 for "night birds" and from 322 to 492 for "doves". 


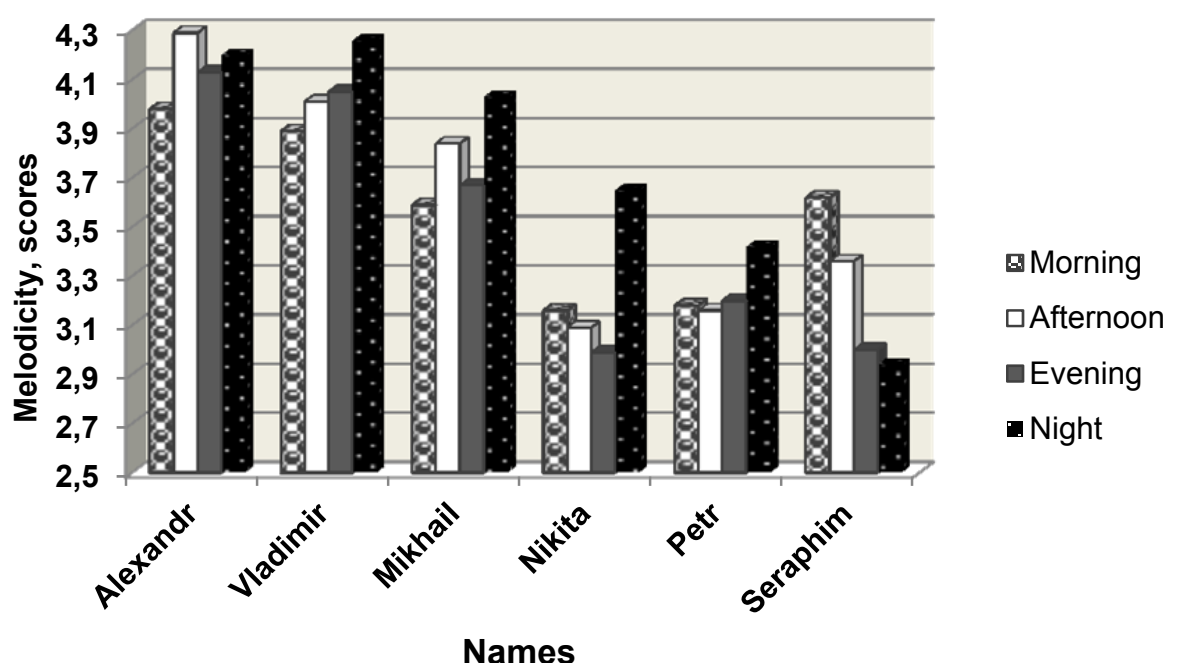

Figure 1. Diurnal variations of the values of the index Melodicity for the names with valid and significant differences between the extremes at $p \leq 0.05 \div 0.001$.

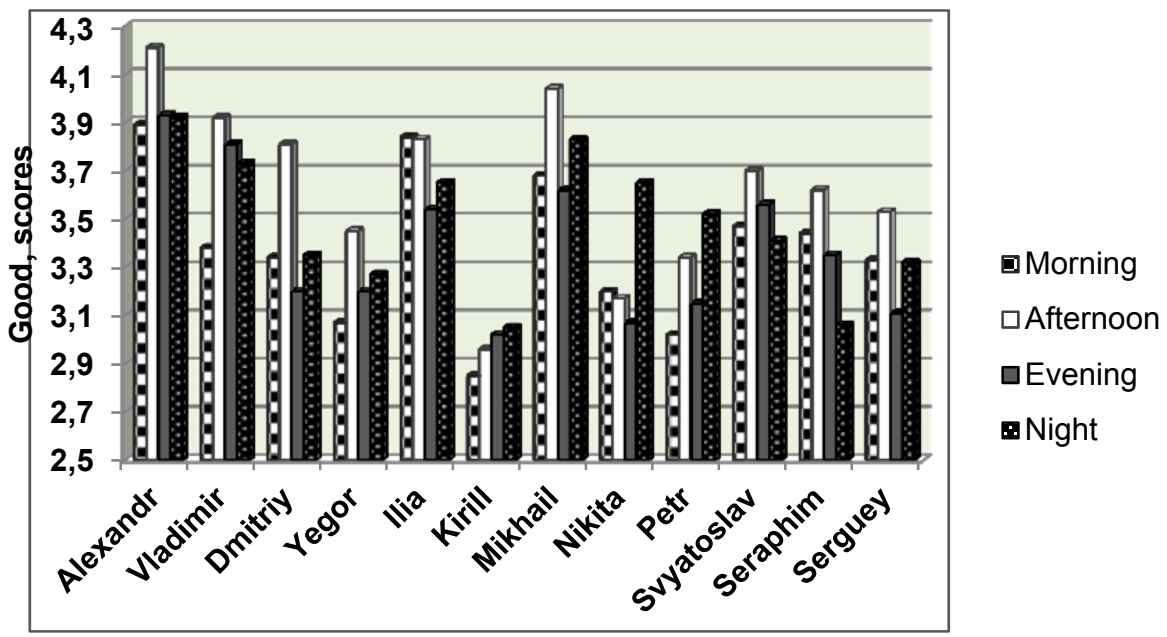

\section{Names}

Figure 2. Diurnal variations of values of the index Good, scores. For most names the difference between the extremes are valid and significant at $p \leq 0.05 \div 0.01$; for llya and Svyatoslav the difference is at $p \leq 0.1$, for Kirill the difference is insignificant.

Variations and the intensity of manifestation of the studied indices of the emotional and color image are significantly different in male and female respondents for the most of the parameters, $p \leq 0.05 \div 0.0001$. For example, men give the 
highest scores to the index Melodicity in the morning and the lowest scores in the evening -3.58 and 3.00 scores, respectively, $p \leq 0.0005$; while women give it the maximal score at night and the minimal score in the morning -3.64 and 3.42 scores, respectively, $p \leq 0.001$. The negative emotional characteristics Rage, Disgust, Fear get higher scores from men than from women, but the scores are the highest in the evening regardless of the respondent's gender (See Figure 3).
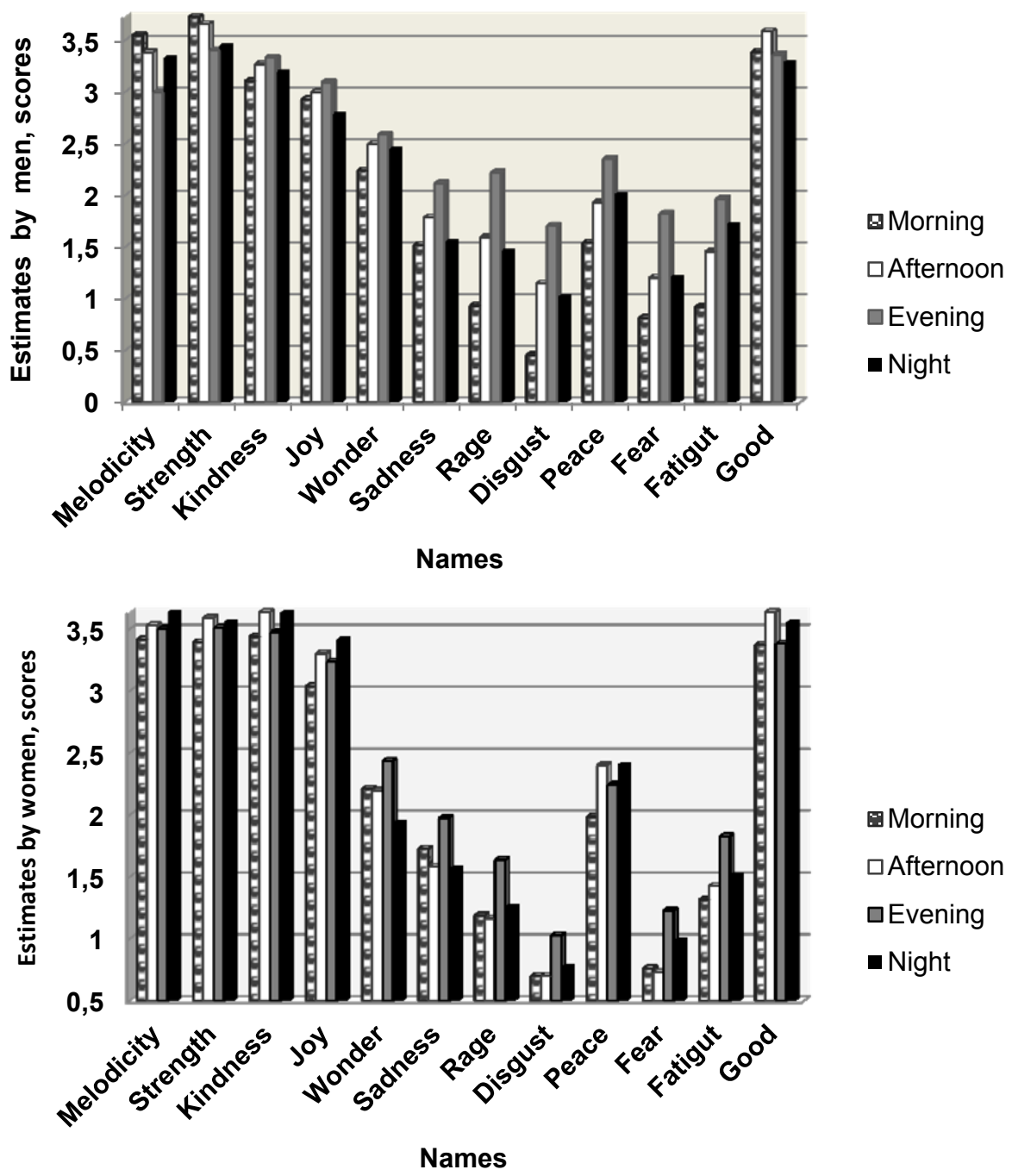

Figure 3. Daily variations of average values of the emotional image for all the names regarding the gender of the respondent. 
The revealed gender differences in scores are not accidental if we take into consideration the fact that daily variations in human cognitive characteristics have been discovered. The parameters and variations of intuitive, logical and combined thinking in men and women have their specific features [3].

The comparative analysis of the results from three diurnal chronotype groups regarding the time of the day also revealed valid and significant differences at $p \leq 0.05 \div 0.0001$ for the most parameters of emotional and color image. This article omits their description, along with the description of color association values from men and women regarding the time of the day and the results for vowels.

Weather and Speech Perception. The correlation analysis of the collected data for the names regarding weather conditions in 23 experimental days from 1 February to 7 June was done for the averaged values of the indices for all the names; for averaged values for each of 12 names; regarding the respondent's gender; separately for several respondents. Analysis was made for vowels in the similar way.

In all the cases valid correlations were detected. Their characteristics and number varied significantly. Examples of correlation pleiades are shown in Figures 4, 6, 7, 8, 9 .

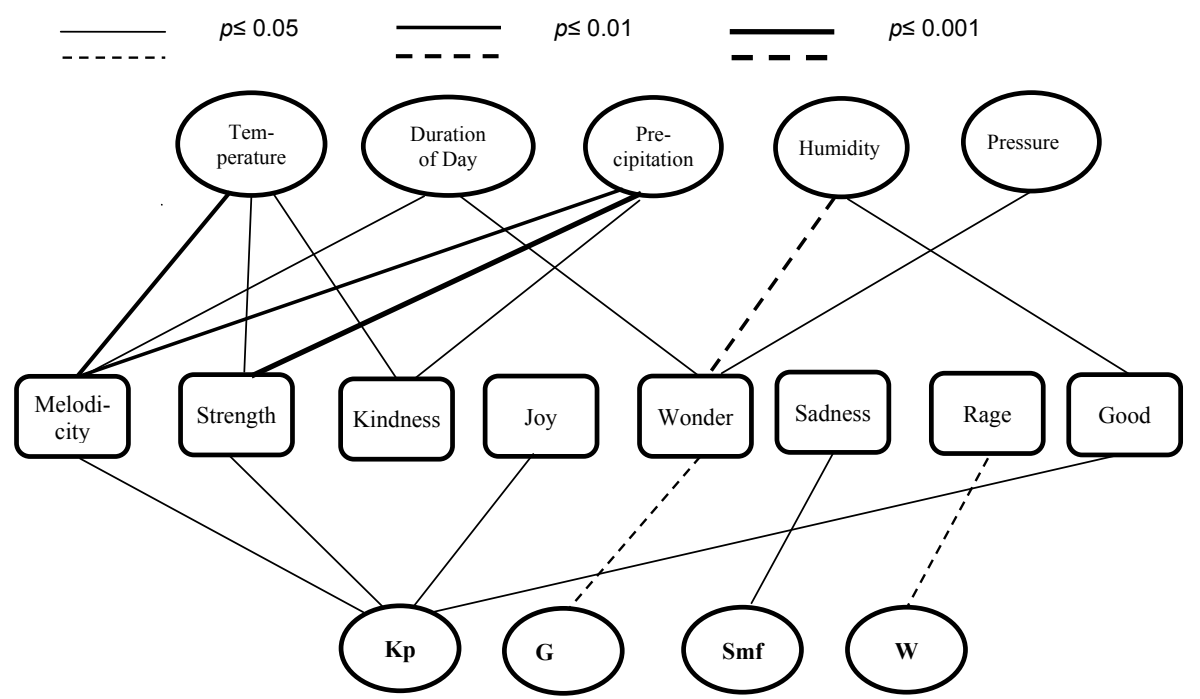

Figure 4. Correlation pleiades for averaged values of the emotional image of all the men names for 23 days of study regardless of the respondents'gender.

Note: hereinafter regional indices are located at the top of the pleiades and cosmic weather indices are located at the bottom. Keys: Kp - geomagnetic disturbance index, G - tidal power index, Smf - Solar magnetic field index, W - Wolf's index. Inverted correlations are shown in a stripple line. 
As you can see at Figure 4, at the time of the study there were correlations for 8 indices of the emotional image. The most influential indices are (in decreasing order) Temperature, Precipitation and geocosmic disturbance Kp. The total number of correlations at $p \leq 0.05 \div 0.001$ is 18 .

Correlation pleiades by gender of respondents look different. There are only 5 correlations at $p \leq 0.05 \div 0.01$ in the respoces by women - for the indices Strength, Sadness, Disgust, Good. The leading indices in the decreasing order are Precipitation, Temperature, Humidity.

For men, there are correlations for each index except the index Sadness - 31 correlation total, at $p \leq 0.05 \div 0.001$. The leading indices are Temperature, Duration of Day, Humidity, in decreasing order. Unlike with women, some correlations in male pleiades are invert. For instance, Disgust and Temperature correlate at $r=0.587 ;-0.702$.

Multiple correlation in the pleiades for male respondents and their diversity from the pleiades for female respondents can be explained with gender specific features of reactivity to natural factors and with enhanced sensitivity of the male organism to environment [3; 7].

Figure 5 illustrates the range of indices related to the duration of day and temperature for male respondents. Correlation coefficient $\boldsymbol{r}$ for the indices Melodicity, Strength, Kindness, Wonder and the index of the duration of the day were $0.811,0.725,0.763,0.755$, respectively, and the index of temperature $-0.715,0.615,0.736,0.570$

The results of the correlational analysis of the averaged values of emotional and color images for each of 12 men names and each vowel are definitely interesting. The pleiades for the emotional images of vowels do not only look different but also have different number of significant correlations in them. For example, vowels A and $\mathrm{b}$ form 9 and 12 correlations while the vowel $И$ forms 29 correlations.

Specific features of the pronunciation of a certain vowel or name obviously influence their perception under definite natural conditions. It is illustrated with the correlation pleiades for three men names, see Figure 6, 7, 8 .

Picture 9 represents correlation pleiades for color images of averaged values of all the names. As you can see, there are multiple correlations with all weather indices except the wind index. At the same time, pleiades for color images and for emotional images obviously mismatch (Figure 4). It is probably caused by the difference in cognitive processes at estimating the parameters of the emotional image of names and at registering color association with the same names. Thus, speech perception and the value shift phenomenon are influenced by changes in the environment. 

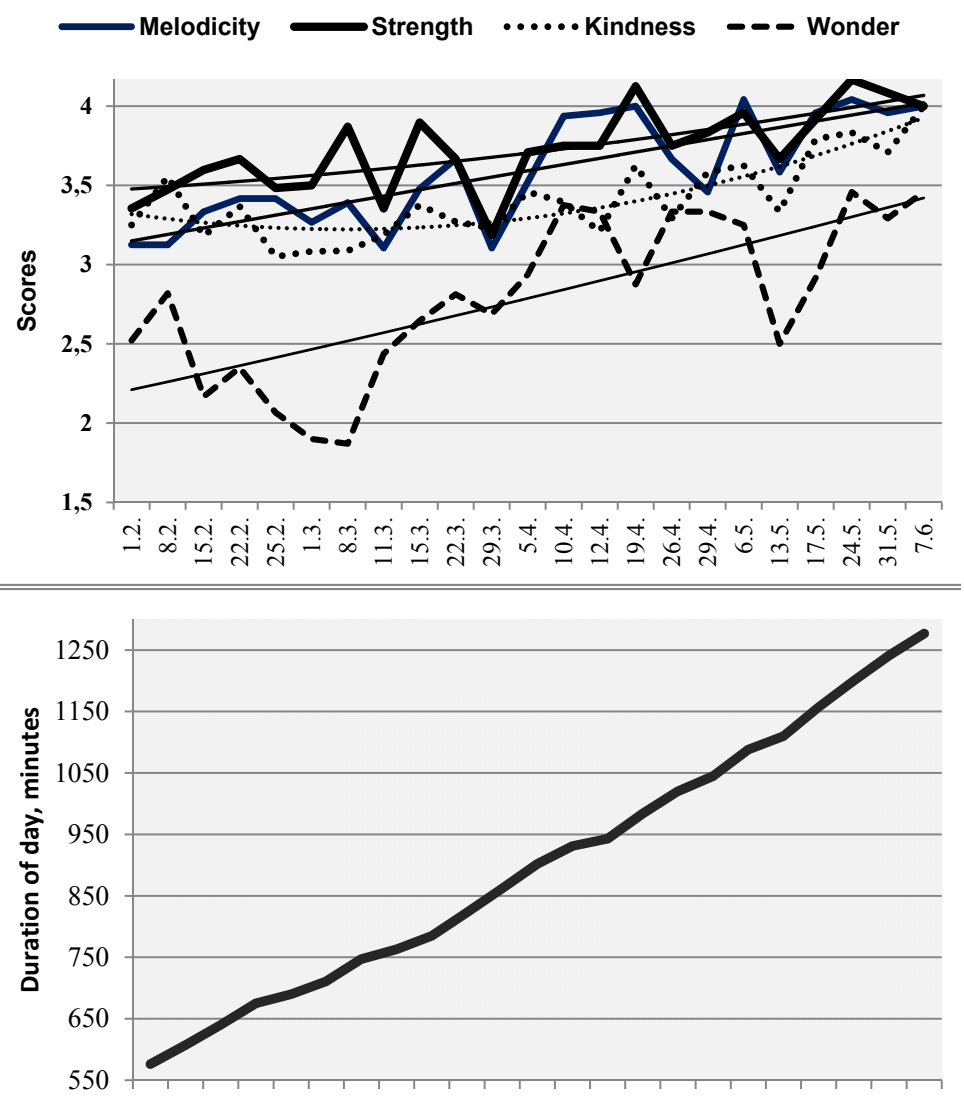

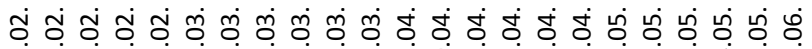

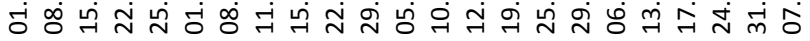

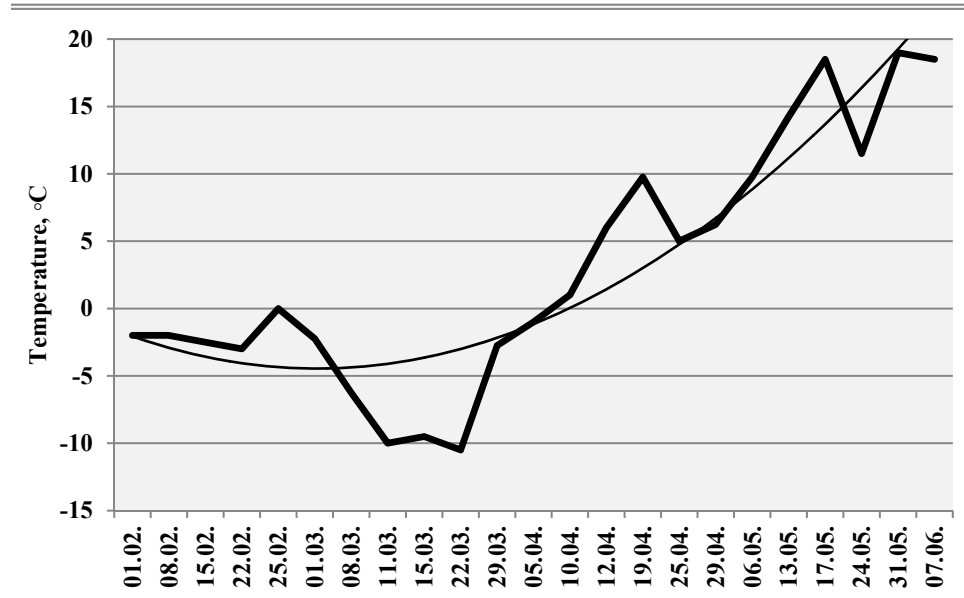

Figure 5. Contingency of average estimates for all the names by male respondents and changes in the day duration and temperature. See the text for details. 


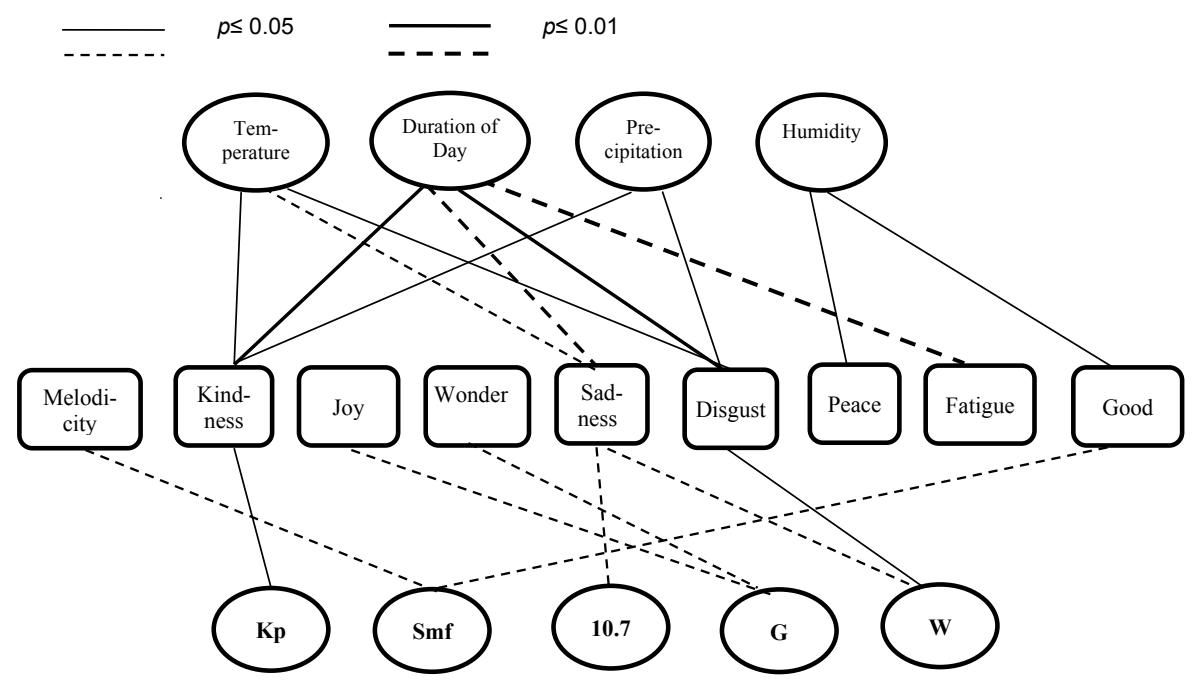

Figure 6. Correlation pleiades for the emotional image of the name Alexandr.

Keys: $\mathrm{Kp}$ - geomagnetic disturbance index, Smf - Solar magnetic field index, 10.7 - radio flux index, $\mathrm{G}$ - tidal power index, $\mathrm{W}$ - solar activity index

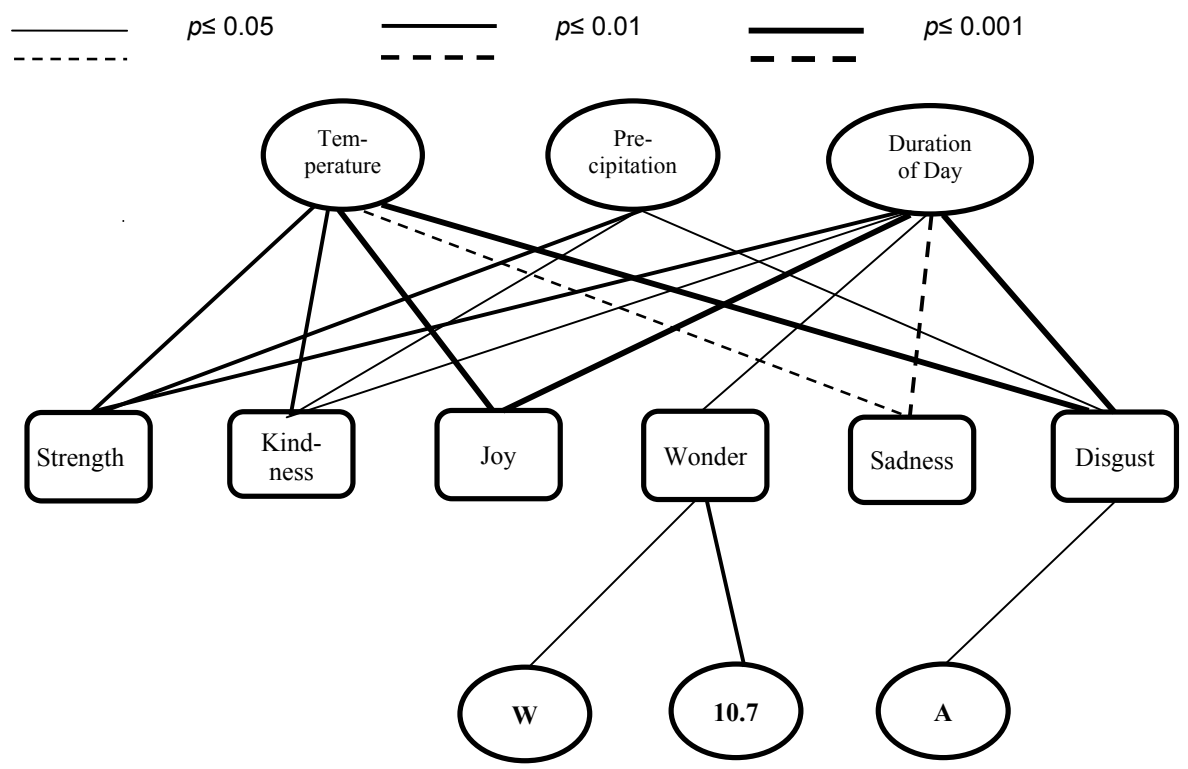

Figure 7. Correlation pleiades for the emotional image of the name Vladimir.

Keys: $\mathrm{W}$ - solar activity index, 10.7 - radio flux index, A - geomagnetic disturbance index 


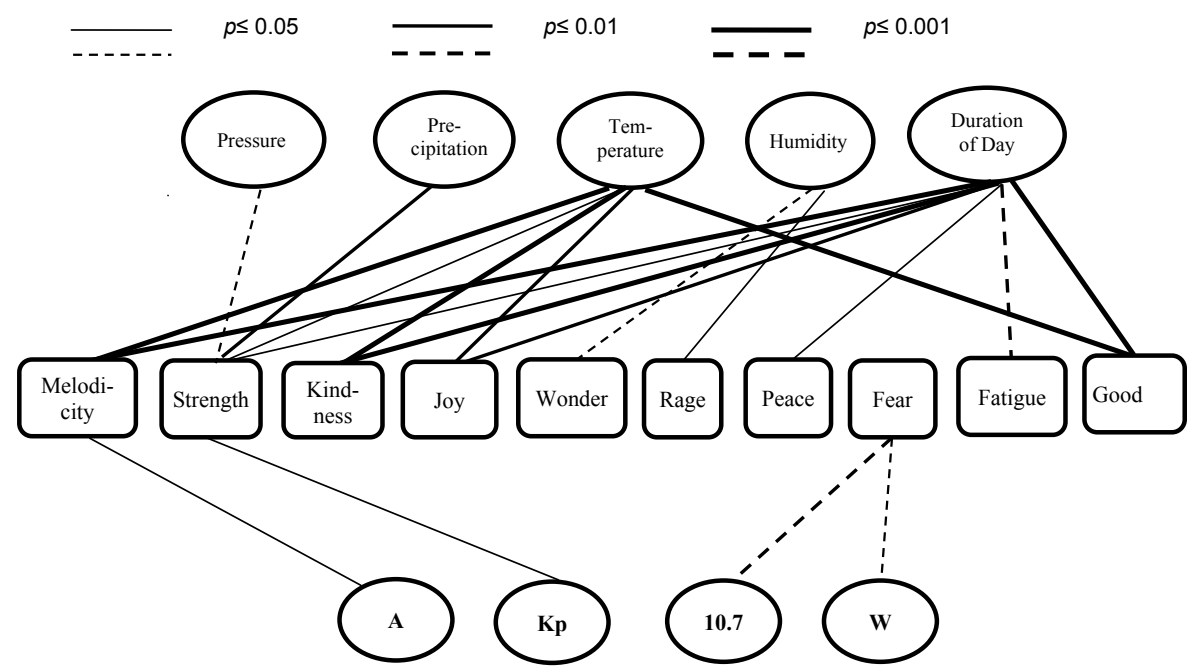

Figure 8. Correlation pleiades for the emotional image of the name Svyatoslav.

Keys: $\mathrm{A}$ and $\mathrm{Kp}$ - geomagnetic disturbance indices, 10.7 - radio flux index, $\mathrm{W}$ - solar activity index

It is known that music and speech are the fastest means for the persons to adjust to changes in their environment. Musical thinking correlates with the main environmental factors. It is reasonable to suggest that the ethnic features of the language, as well as its evolution, are also inseparably associated with natural environment [4]. For instance, in extremely cold conditions in the north of the Canadian Arctic one can die if he or she takes too deep a breath. This is why, when learning the Eskimo language, one has to hold a pencil between the teeth and try not to let it fall out while speaking [11]. Therefore, people, living in different climate conditions develop languages with fundamentally different frequencies of sounds.

Language plays a crucial role in the adaptation to climate, weather and other ecological factors of the region where it has been developed. When the human body resistance to environmental conditions approaches its limits, one of the ways to sustain healthy functioning is switching to the language that aligns body and nature and returning to the representational perception and designation of the world, which was commonly found in ancestors. It explains the massive tendency to speak native languages and to pick up local languages of the region people live in [10]. 


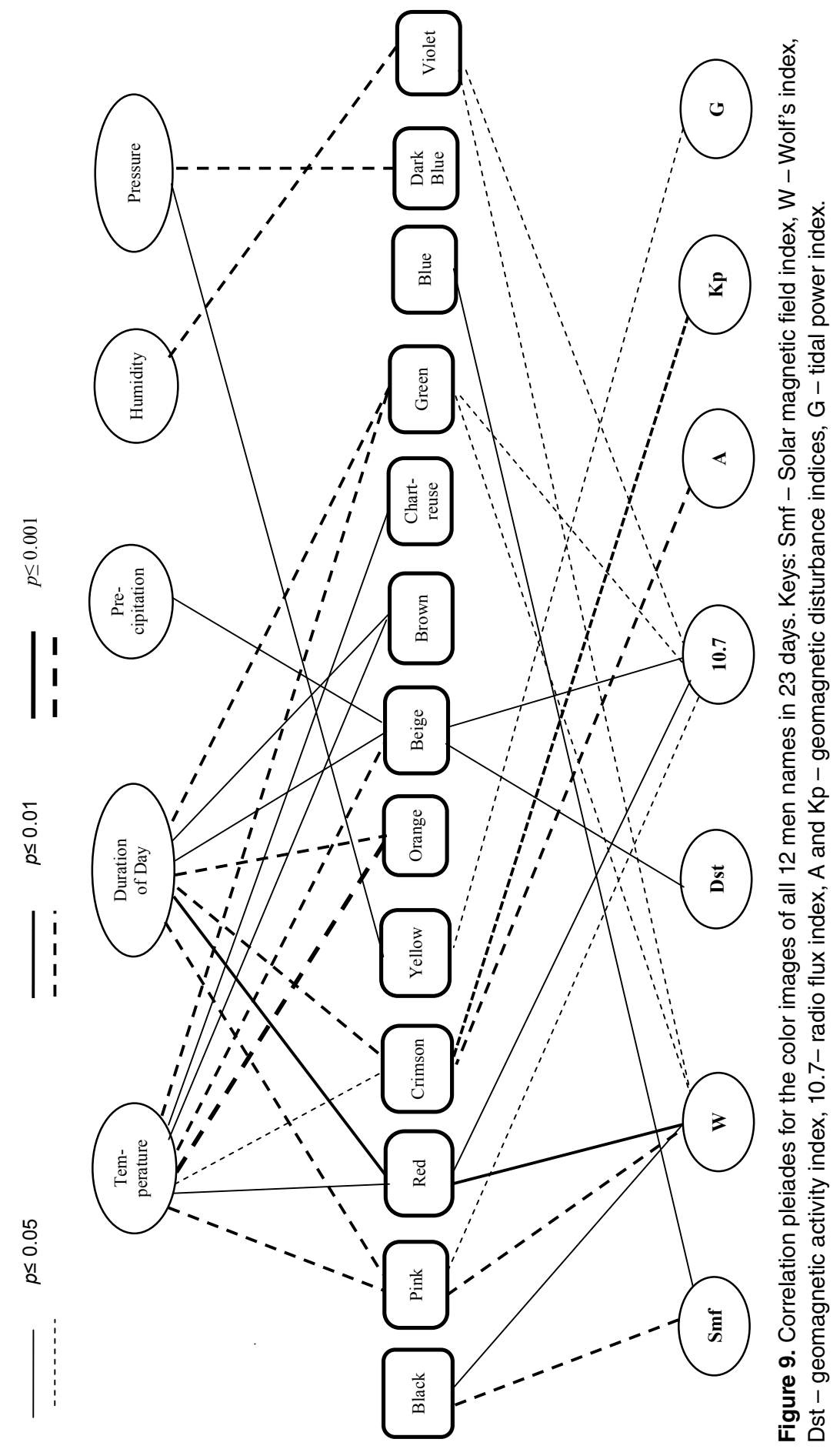




\section{CONCLUSION}

There are valid and significant adaptive changes in the parameters of images of the names and vowels related to the time of the day and season and to weather conditions. Correlation between changes in emotional and color images of men names and in weather indices was discovered. Therefore, the value shift phenomenon and the speech perception itself depend on environmental conditions. The gender and diurnal chronotype influence on the manifestation of parameters of the multicomponent image of the name in regard to the time of the day and weather conditions.

\section{REFERENCES}

1. Ananyev B. G. (1997). About problems in modern human studies. Moscow, Nauka.

2. Bragina N. N., Dobrokhotova T. A. (1977). Functional asymmetry and psychopathology of focal brain lesion. Moscow, Meditsina.

3. Volchek O. D. Geocosmos and Person: a monograph. Saint Petersburg, RGPU Publishing, 2006.

4. Volchek O. D. (2011). Sounds, Words, Names. Saint Petersburg, «Knizhniy Dom».

5. Volchek O. D. (2013). Phonetic meaning and time of day. Theory and Practice of Verbal Communication. Papers of the 5th Int'l Research and Methodology Conference June 20-21, 2013. Ass.Editor T.M.Rogozhnikova. Ufa, UGATU, 72-74.

6. Zhuravlev A. P. (1974). Phonetical meaning. Leningrad, LGU Publishing.

7. Geodakyan V. A. (2000). Evolutionary chromosomes and evolutional sex dimorphism. Izvestiya AN, Biological series, № 2, 133-148.

8. Putilov A. A. (2003). Night birds, early birds and others. Novosibirsk, Novosibirsk Uni. Publishing.

9. Florenskiy P. A. (1993). Names. The archives of the priest Pavel Florenskiy. Kostroma, Kupina.

10. Khasnulin V. I. (2009). Ethnic characteristics of psychophysiology of indigenous inhabitants of the North as basis for survival in extreme environment. Problems of health maintenance in the North and Siberia. Moscow, 36-54.

11. Hersch G. I. (2009).Cultural suicide in Nunavut, or Why Eskimos don't have words and concepts describing future. Problems of health maintenance in the North and Siberia. Moscow, 185-203.

12. Volchek O. D. (2013). Environmental Surrounding and Perception of Speech. Papers on Anthropology XXII. Tartu, 264-273. 
$134 \mid$ O. D. Volchek

Corresponding author:

Olga D. Volchek

Saint Petersburg Institute of Humanities

Ph.D. in Psychology, associate professor

190000, Russia, Saint Petersburg, Kazanskaya 45-81.

E-mail:volchekod@mail.ru 